\title{
Embarazo heterotópico: Presentación de un caso
}

\author{
Andrés Sarmiento*; Luis Eduardo Silva**; Anaheim Jordán***; Mauricio Carrillo****
}

\begin{abstract}
RESUMEN: Se presenta el caso de una paciente con gestación heterotópica. Se revisan aspectos relacionados con la etiología, diagnóstico y manejo de esta entidad. Se hace énfasis en el aumento de la incidencia de esta patología, especialmente en pacientes sometidas a técnicas de reproducción asistida. Las estadísticas previas donde se refería a esta entidad como infrecuente deben ser revaluadas.
\end{abstract}

PALABRAS CLAVES: Heterotópico, fertilización in-vitro, ecografía transvaginal.

SUMMARY: A case of a patient with a heterotopic pregnancy is presented. Aspects related to etiology, diagnosis and management of this entity are reviewed. Emphasis is made in the high incidence of heterotopic pregnancy associated with reproductive assisted techniques. The previous statistics that referred this entity as infrequent must be revaluated.

KEY WORDS: Heterotopic, IVF, transvaginal ultrasonography.

\section{Introducción}

La presencia simultánea de embarazo intra y extrauterino conocida como embarazo heterotópico o combinado es un evento raro pero a la luz de la obstetricia moderna, cada vez más frecuente. El primer caso de embarazo heterotópico fue reportado por Duverney en 1708 durante una autopsia (1). Desde entonces el embarazo combinado ha sido considerado como un evento exótico pero a la vez potencialmente fatal.

Históricamente la ocurrencia de embarazo heterotópico ha sido referida como muy baja. Estadísticas de 1948 reportan una incidencia tan baja como de 1:30 000 embarazos (1). Existen referencias recientes de cifras que oscilan entre 1:1 300 a 1: $15 \cdot 600$ embarazos (2-3). Este aumento en la frecuencia puede verse asociado a diferentes fenómenos que definitivamente están ligados al ingreso de las técnicas de reproducción asistida a la práctica obstétrica. Desde 1985 a la fecha han aparecido en la literatura médica múltiples referencias acerca del uso de inductores de la ovulación y técnicas quirúrgicas de reproducción asistida como factores asociadas a la ocurrencia de gestaciones heterotópicas. Ciertamente, la incidencia de embarazos combinados puede ser hasta del $1 \%$, cuando se usa esta tecnología (3). Otro factor que puede ser importante es el aumento de los casos de enfermedad inflamatoria pélvica; factor que claramente se ha asociado a la aparición de embarazo extrauterino (4-5).

La aparición de una gestación heterotópica "espontánea" es decir sin antecedentes de riesgo, continúa siendo

\footnotetext{
* Médico Ginecobstetra. Coordinador Académico Unidad de Medicina Materno-Fetal. E.C.M. Hospital Simón Bolívar.

** Médico Ginecobstetra. E.C.M. Hospital Simón Bolivar.

*** Residente III Ginecobstetricia. E.C.M. Hospital Simón Bolívar.

**** Residente II Ginecobstetricia. E.C.M. Hospital Simón Bolivar
}

un evento obstétrico exótico. Este hecho potencialmente puede verse asociado a demoras diagnósticas y desafortunadamente a morbimortalidad materno-fetal.

\section{Caso Clínico}

Paciente de 42 años quien consulta al servicio de urgencias por cuadro de dolor abdominal. La paciente refiere dolor insidioso tipo cólico de localización hipogástrica de un mes de evolución que se exacerba 2 horas antes del ingreso. Como antecedentes obstétricos es una G:5 P:3 A:1 V:3 con una edad gestacional de 13.5 semanas calculadas a partir de una FUR no confiable por uso de progestágenos IM. La paciente no refería control prenatal en el embarazo actual, sin embargo trae informe ecográfico de primer trimestre que reporta un embarazo intrauterino normal de 7 semanas. Otros antecedentes personales eran negativos.

Al examen físico de ingreso se encuentra una paciente obesa, diaforética y álgica, con palidez mucocutánea. TA: 103/65 FC: 80 lpm. Examen cardiopulmonar satisfactorio. Abdomen blando, depresible, doloroso a la palpación en hipogastrio. RsIs +++ . No signos de irritación peritoneal. El examen ginecológico es normal para una gestación de aproximadamente 13 semanas. No hay evidencia de sangrado genital. Se solicitan laboratorios de rutina y una ecografía obstétrica.

Se practica un estudio obstétrico con sonda transvaginal el cual reporta un embarazo intrauterino por polo fetal único, vivo y activo. Su edad gestacional estimada a partir de DBP y CRL corresponde a 13 semanas y 5 días. FCF: $154 \mathrm{lpm}$. Valoración anatómica satisfactoria. Placenta anterior normoinserta grado O/III. OCI cerrado con canal endocervical largo. A la valoración pélvica se advierte una gran colección de ecogenicidad mixta que ocupa el fondo de saco y que 
sugiere sangre. Se complementa con estudio abdominopélvico, visualizándose un segundo polo fetal viable, desalojado de la pelvis y discretamente desviado hacia el flanco derecho materno. Presenta una biometría similar a la del primer gemelo. FCF: $156 \mathrm{lpm}$. Placenta grado O/III que se localiza sobre imágenes de ecogenicidad mixta y mal definidas que sugieren asas intestinales o trompa derecha. Nuevamente mediante ultrasonido transvaginal se demuestra el contorno uterino y se corrobora la localización extrauterina del segundo polo fetal.

Con estos hallazgos se hace una impresión diagnóstica de embarazo heterotópico por embarazo intrauterino viable de 13 semanas y 5 días, con gestación ectópica tubárica derecha rota vs implantación abdominal (?). Los laboratorios demuestran una $\mathrm{Hb}$ de $6.2 \mathrm{gm} \mathrm{\%} \mathrm{y} \mathrm{Hct} \mathrm{de}$ $21 \%$. Química sanguínea, pruebas de coagulación y PdO son normales. La paciente es programada para cirugía siendo sometida a una preparación aguda de colon previendo la posibilidad de una gestación abdominal. Se transfunden 4 unidades de GR empaquetados. La paciente es llevada a cirugía donde BAG se práctica laparotomía mediante abordaje mediano infraumbilical. Como hallazgos se evidencia embarazo ectópico ampular derecho roto con hemoperitoneo de aproximadamente $2000 \mathrm{cc}$. Feto vivo de sexo masculino con CRL de 9 cms. La placenta se encuentra implantada sobre la trompa comprometiéndola en su totalidad. No hay asas abdominales interesadas. Utero grávido de tamaño normal para la edad gestacional. Se práctica salpingectomía derecha y lavado de cavidad.

El postoperatorio evoluciona satisfactoriamente, se ordena salida en el 4o. día POP con control por consulta externa de alto riesgo. El embarazo evoluciona satisfactoriamente.

\section{Discusión}

La incidencia de embarazo heterotópico ha aumentado dramáticamente en los últimos 50 años; cuando inicialmente fue reportada como de 1:30000 embarazos. Actualmente existen referencias que indican como 1-4 de cada 100 pacientes sometidas a técnicas de fertilización in-vitro con transferencia de embriones, puede presentar una gestación heterotópica. La incidencia de embarazo combinado es 400 veces más alta en presencia de técnicas de reproducción asistida que en gestaciones espontáneas (7-10, 12).

Asimismo se ha visto como la transferencia de más de 4 embriones aumenta el riesgo de gestación combinada. (4, 11). Si el riesgo global de gestación heterotópica secundaria a fertilización in vitro con transferencia de cuatro embriones ha sido estimado en 1:119, la transferencia de más de 4 embriones modifica esta cifra a 1:45 embarazos (13). Sin embargo los factores que pueden explicar este fenómeno no solamente se limitan al número de embriones transferidos. La colocación inadvertida del catéter dentro del ostium de la trompa, un excesivo volumen o presión hidrostática durante la transferencia y una posible migración retrógrada de embriones como resultado de contracciones uterinas, han sido referidos como otros posibles factores etiológicos asociados $(13-14,20)$.
Aún cuando los eventos etiológicos no han sido plenamente esclarecidos, muchos de los factores son compartidos con aquellos referidos para el embarazo ectópico. La enfermedad inflamatoria pélvica con su concomitante daño tubárico postinfección ha sido referido como un factor etiológico potencial en aproximadamente $45 \%$ de los casos de embarazos ectópicos. En pacientes con EPI el riesgo de presentar un embarazo extrauterino aumenta en 7-10 veces (4-5). La pérdida de la anatomía tubárica y de la integridad funcional altera la actividad fisiológica normal de la trompa y predispone a sitios anormales de implantación.

Asimismo se ha asociado como factor etiológico del embarazo múltiple dicigoto, en el cual ambos óvulos provenientes de uno o dos folículos son fertilizados en el mismo coito $(6,16)$. Otros posibles factores son la superfecundación, la superfetación y la hiperestimulación ovárica. La ocurrencia de embarazo combinado en asocio al uso de gonadotropinas ha sido referido como de hasta 1:300; y de 1:100 con el uso del citrato de clomifeno $(8,10)$.

Habitualmente el diagnóstico del embarazo combinado puede ser hecho a través del seguimiento ecográfico transvaginal rutinario del primer trimestre. Ya que la mayoría de casos de embarazos logrados a través de técnicas de reproducción asistida son celosamente seguidos durante las primeras semanas de gestación en busca de viabilidad, se puede llegar a lograr un diagnóstico muy temprano. Un alto porcentaje de casos son diagnosticados entre las 7 y 10 semanas de gestación a través del ultrasonido transvaginal. Las imágenes más frecuentemente visualizadas son masa anexial y líquido libre en el fondo de saco en presencia de saco gestacional intrauterino. (1819). El ultrasonido transvaginal ha desplazado casi por completo la ecografía convencional transvesical para el diagnóstico y seguimiento de estos casos. Con su utilización el índice de certeza diagnóstica debe ser alto (20).

Clínicamente se debe sospechar embarazo heterotópico en presencia de una o varias de las siguientes:

1. Embarazo con antecedente de técnicas de reproducción asistida.

2. Ausencia de sangrado postsupresión.

3. Persistencia de signos y/o síntomas de embarazo después de un legrado obstétrico, de la excisión de un embarazo ectópico o la administración de fármacos abortivos.

4. Persistencia de títulos de HCG después de un legrado obstétrico.

5. Títulos inusitadamente altos de HCG con saco gestacional único intrauterino.

6. Cuadro clínico de abdomen "quirúrgico" con masa anexial blanda en presencia de una gestación intrauterina.

7. Ausencia de manchado y/o sangrado genital en presencia de un embarazo ectópico.

8. Utero aumentado de tamaño en presencia de embarazo ectópico.

9. Dolor abdominal y hemoperitoneo con antecedente de un legrado obstétrico sin complicaciones.

El manejo una vez se hace el diagnóstico debe ser quirúrgico. La escisión del saco extrauterino previene la ruptura del mismo con el consecuente hemoperitoneo. Las posibilidades del tratamiento quirúrgico dependen de la edad gestacional al momento del diagnóstico. En gestaciones 
tempranas la laparoscopia operatoria debe ser la técnica de elección. En gestaciones mayores o en ruptura del embarazo extrauterino la laparotomía está indicada. Existen referencias anecdóticas en la literatura médica acerca de la resistencia de embarazos extrauterinos heterotópicos al uso de abortivos como el mifepristone (RU-486). (16-17).

Mientras la tasa de mortalidad para el embarazo extrauterino es superior al 95\%, la del embarazo intrauterino oscila entre $45 \%$ al $65 \%$. La incidencia de mortalidad materna es menor el $1 \%$ en casos de embarazo ectópico tubárico. Cuando el embarazo heterotópico es de localización intrabdominal esta mortalidad puede ser hasta del $6 \%(17-18,20)$.

\section{Conclusión}

El presente escrito reporta la ocurrencia de un embarazo heterotópico "espontáneo" sin la mediación de apa- rentes factores de riesgo. El caso ilustra la importancia de la sospecha clínica, del ultrasonido transvaginal y de la intervención quirúrgica agresiva como factores de vital importancia en el manejo de estas pacientes.

A la fecha los ginecobstetras debemos ser conscientes que las estadísticas previas que reportaban el embarazo heterotópico como una patología exótica deben ser revaluadas. A la luz de la obstetricia moderna donde la infección pélvica y las técnicas de fertilización asistida son cada vez más comunes, el embarazo combinado siempre deberá ser considerado como una posibilidad diagnóstica.

Solamente bajo estos parámetros de sospecha clínica temprana se agilizará un enfoque diagnóstico oportuno, se disminuirá la posible morbimortalidad derivada de un diagnóstico tardío y se reducirán las posibles secuelas.

\section{BIBLIOGRAFIA}

1. De Voe RW., Pratt JH. Simultaneus intrauterine and extrauterine pregnancy. Am. J. Obstet. Gynecol. 1948; 56: 1119-1126.

2. Fernández H., Lelaidier C., Doumerc S. Nonsurgical treatment of Heterotopic pregnancy: a report of six cases. Fertility and Sterility 1993; 60: 428-432.

3. Richards SR., Stempel LE., Carlton BD. Heterotopic pregnancy: reappraisal of incidence. Am. J. Obstet. Gynecol. 1982; 142: 928930.

4. Risk B., Tan SL., Morcos S et al. Heterotopic pregnancies after in vitro fertilization and embryo transfer. Am. J. Obstet. Gynecol. 1991; 164 : 161-164.

5. Loret JR et al. Cornual Heterotopic pregnancy and cornual resection after in vitro fertilization/embryo transfer. A report of two cases. J. Reprod. Med. 1995; 40: 606-610.

6. Reece EA., Petrie RH., Sirmans MF et al. Combined intrauterine and extrauterine gestations: A review. Am. J. Obstet. Gynecol. 1983; 146: 323-329.

7. Walker DJ., Clarke TC., Kennedy CR. Heterotopic ectopic and intrauterine pregnancy after embryo remplacement. Br. J. Obstet. Gynaecol. 1993; 100: 1048-1049.

8. Lewis PL, Morel M, Scotti RJ. Heterotopic intrauterine and tubal pregnancy complicated by pulmonar embolism. A case report. J. Reprod. Med. 1994; 39: 417-418.

9. Goldman GA., Fisch B., Ovadia J., Tadir Y. Heterotopic pregnancy after assited reproductive technologies. Obstet. Gynecol. Surv. 1992; 47: 217-221.

10. Berger MJ., Taymor ML. Simultaneous intrauterine and tubal pregnancies following ovulation induction. Am. J. Obstet. Gynecol.1972; 113: 812-813.
11. Tummon IS., Withmore NA., Daniel SA et al. Transferring more embryos increases risk of heterotopic pregnancy. Fertil Steril 1994; 61: 1065-1067.

12. Goldman JA., Dicker D., Dekel A et al. Sucessful management and outcomen of heterotopic triplet gestation: Twin tubal and surviving intrauterine pregnancy. J In vitro Fert. 1991; 8: 300.

13. Sherer DM., Scibetta JJ., Sanko SR. Heterotopic quadruplet gestation with laparoscopic resection of ruptured interstitial pregnancy and subsequent sucessful outcome of triplets. Am. J. Obstet. Gynecol. 1995; 172: 216-217.

14. Fa EM., Gerscovich EO. High resolution ultrasound in the diagnosis of heterotopic pregnancy: Combined transabdominal and transvaginal approach. Br. J. Obstet. Gynaecol. 1993; 100: 871-872.

15. Singh KB., Wise R., Otterson Wn et al. Asyntomatic Heterotopic ovarian pregnancy. Southern. Med. J. 1992; 85: 53-54.

16. Levin JH., Lacarra M., D'Ablaing $G$ et al. Mifepristone (RU486) failure in an ovarian heterotopic pregnancy. Am. J. Obstet. Gynecol. 1990; 163: 543-544.

17. Hirsch E., Cohen L., Hecht BR. Heterotopic pregnancy with discordant ultrasonic apperance of fetal cardiac activity. Obstet. Gynecol. 1992; 79: 824-825.

18. Ron-El R., Langer R., Herman A et al. Term delivery following midtrimestrer ruptured cornual pregnancy with combined intrauterine pregnancy. Case report. Br. J. Obstet. Gynaecol. 1988; 95: 619-620.

19. Hann LE., Bachman DM., McArdle CR. Coexistent intrauterine and ectopic pregnancy: A reevaluation. Radiology 1984; 152: 151-154.

20. Rein MS., Di Salvo DN., Friedman AJ. Heterotopic pregnancy associated with in vitro fertilization and embryo transfer: A possible role for routine vaginal ultrasound. Fertil Steril 1989; 51: 1057-1058. 